\title{
Outcomes of hypofractionated stereotactic body radiotherapy boost for intermediate and high-risk prostate cancer
}

\author{
Mekhail Anwar ${ }^{1 *} \mathbb{D}$, Vivian Weinberg ${ }^{2}$, Zachary Seymour ${ }^{3}$, I. Joe Hsu², Mack Roach III ${ }^{4}$ and Alex R. Gottschalk ${ }^{2}$
}

\begin{abstract}
Background and purpose: Treatment of intermediate and high-risk prostate cancer with a high BED has been shown to increase recurrence free survival (RFS). While high dose rate (HDR) brachytherapy, given as a boost is effective in delivering a high BED, many patients are not candidates for the procedure or wish to avoid an invasive procedure. We evaluated the use of stereotactic body radiotherapy (SBRT) as a boost, with dosimetry modeled after HDR-boost.

Material and methods: Fifty patients were treated with two fractions of SBRT (9.5-10.5 Gy/fraction) after 45 Gy external-beam radiotherapy, with 48 eligible for analysis at a median follow-up of 42.7 months.

Results: The Kaplan-Meier estimates of biochemical control post-radiation therapy (95\% Confidence Interval) at 3, 4 and 5 years were $95 \%$ (81-99\%), $90 \%$ (72-97\%) and $90 \%$ (72-97\%), respectively (not counting 2 patients with a PSA bounce as failures). RFS (defined as disease recurrence or death) estimates at 3, 4 and 5 years were $92 \%$ (77$97 \%), 88 \%(69-95 \%)$ and $83 \%(62-93 \%)$ if patients with PSA bounces are not counted as failures, and were $90 \%$ (75-96 \%), $85 \%$ (67-94 \%) and $75 \%$ (53-88 \%) if they were. The median time to PSA nadir was 26.2 months (range $5.8-82.9$ months), with a median PSA nadir of $0.05 \mathrm{ng} / \mathrm{mL}$ (range $<0.01-1.99 \mathrm{ng} / \mathrm{mL}$ ). 2 patients had a "benign PSA bounce", and 4 patients recurred with radiographic evidence of recurrence beyond the RT fields. Treatment was well tolerated with no acute G3 or higher Gl or GU toxicity and only a single G3 late GU toxicity of urinary obstruction.
\end{abstract}

Conclusions: SBRT boost is well-tolerated for intermediate and high-risk prostate cancer patients with good biochemical outcomes and low toxicity.

Keywords: Stereotactic body radiotherapy, Boost, Prostate cancer

\section{Introduction}

Patients with intermediate and high-risk prostate cancer have poorer clinical outcomes than patients with lowrisk prostate cancer, and in need of more intensified therapeutic options. Although the role of hormone therapy (HT) [1] in increasing recurrence free survival (RFS) and overall survival (OS) has been well established, the optimum dose and fractionation of radiation is still being investigated. Multiple randomized trials have demonstrated an increased RFS with dose escalation [2-4], albeit no difference in OS. Coupled with a potentially

\footnotetext{
* Correspondence: mekhail.anwar@ucsf.edu

Presented in part at ASTRO 2013 Atlanta GA, as an oral presentation.

'Department of Radiation Oncology, University of California San Francisco,

1825 4th Street, San Francisco, CA 94158, USA

Full list of author information is available at the end of the article
}

low alpha-beta ratio $[5,6]$ for prostate adenocarcinoma, recent strategies for improving clinical outcomes have focused on hypofractionated radiotherapy to deliver a higher bioequivalent dose (BED) over conventionally fractionated (1.8-2 Gy/fraction) external beam radiotherapy (CF-EBRT), as well as shortening treatment regimens for increased cost-effectiveness [7]. These efforts led to use of high dose rate brachytherapy (HDR), both as a boost [8-10] and as monotherapy [11-14]. Further supporting the use of hypofractionated radiotherapy, a lower PSA nadir has been associated with increased freedom from biochemical failure [15-18] in prostate cancer, and the results of studies employing HDR demonstrate PSA nadirs in the range of $0.1 \mathrm{ng} / \mathrm{mL}$ [9], lower than the $0.5 \mathrm{ng} / \mathrm{mL}$ level typically associated with CF-EBRT. 
Unfortunately, HDR requires an invasive operative procedure and many prostate cancer patients are often not candidates due to their age, co-morbidities, or preference not to have surgery. Therefore, our goal was to develop and demonstrate a non-invasive method of delivering a dose and fractionation equivalent to an HDR boost using stereotactic body radiotherapy (SBRT) for patients with intermediate and high-risk prostate cancer.

While SBRT has a long history in the treatment of CNS and thoracic malignancies, several recent studies have demonstrated its feasibility and applicability for treatment of low and intermediate risk prostate cancer as monotherapy [19-21] with minimal toxicity [22], but few studies have rigorously examined SBRT in the boost setting. Our hypothesis was that the SBRT delivered in 2 fractions of 9.5 to 10.5 Gy should result in equivalent biochemical control and toxicity profile as HDR without the need for an invasive, operative procedure. Dosimetry was modeled after RTOG 0321, replicating the rapid delivery of high doses, as well as the ability to achieve tight conformality, sparing nearby normal tissues. This study differs from previous studies in that we present the results of SBRT as a boost after CF-EBRT in a higher risk group of patients and discuss PSA kinetics, biochemical control, toxicity and patterns of recurrence.

\section{Patients and methods}

Ethics, consent, and permissions

Patients with intermediate and high-risk prostate cancer treated with SBRT as a boost from August 2006 to August 2012 were followed with approval from the XXXX Committee on Human Research.

\section{Patient selection}

Patients with biopsy proven prostate adenocarcinoma were seen in a multidisciplinary clinic and counseled on treatment options, including surgery and radiotherapy. Patients were eligible for this study if they were intermediate (Gleason $3+4$ or $4+3$ ) or high (Gleason $\geq 8$ ) grade, node negative, without metastases, and treated with SBRT as a boost to the prostate after a course of CF-EBRT to the prostate and seminal vesicles (with or without whole pelvic radiation). Of the 50 eligible patients, 48 patients met these criteria and 2 were excluded due to no available PSA follow-up. T-stage ranged from T1c to T3b and pre-treatment PSA arranged from 3.6 to $150 \mathrm{ng} / \mathrm{mL}$. Patients were $\geq 18$, with median age of 70 (range 47.1-85.2) years. Patients were eligible for treatment with or without hormone therapy (HT).

\section{Treatment}

Of the 48 eligible patients, 45 had information regarding HT available. The majority (42) of these patients received HT, consisting of 2 months of neoadjuvant HT with Lupron and Casodex or Firmagon, followed by 5 weeks of HT. Thirty of these patients were subsequently treated with $>3$ additional months of adjuvant HT, with a goal of 4-6 months of HT for all intermediate risk patients, and 2 years of HT for high risk patients [23]. HT was discontinued early if the patient experienced side effects significantly affecting their quality of life. The two SBRT fractions were delivered either consecutively or every-other-day [24].

\section{Radiation technique}

The specifics of the SBRT technique have been described previously [25], but briefly, the dose and fractionation are based on the XXX HDR boost experience [26], with 9.5 Gy or 10.5 Gy in 2 fractions prescribed to an isodose of $60-80 \%$. This corresponds to a biological equivalent dose (BED) of 278 to 336 with an alpha/beta of 1.5 or a BED of 158 to 189 with an alpha/beta of 3 . A $2 \mathrm{~mm}$ planning treatment volume (PTV) expansion is used, except posteriorly, where the prostate abuts the rectum, the expansion is $0 \mathrm{~mm}$. The posterior expansion is reduced to mitigate rectal toxicity. Patients were initially treated with external beam radiotherapy to the whole pelvis, extending to between L4/L5 and L5/S1 as the superior border, and including the internal and external iliacs and obdurator nodes to 45 Gy in 25 fractions. The prostate and seminal vesicles were treated concurrently to 45-50 Gy using a simultaneous integrated boost (SIB) to the prostate and seminal vesicles of 2 Gy per fraction. The whole pelvis was treated if the risk of pelvic nodal involvement was $>15 \%$ by the Roach equations [27]. Aside from the use of an SIB, radiotherapy planning for the conventionally fractionated portion was done as in RTOG 0321 [8]. Because gold seed fiducials are used for daily alignment, the PTV margin did not exceed $1 \mathrm{~cm}$. Prior to radiation treatment, 3 fiducial markers were inserted into the prostate, enabling realtime tracking of and automatic beam adjustment for inter- and intra-fraction prostate motion, for whole pelvic RT and SBRT, respectively. Imaging for SBRT was taken once every $60 \mathrm{~s}$.

Treatment planning was completed with dosimetric constraints similar to those reported by Fuller [28] for inverse-planned HDR brachytherapy with PTV V100\% $>95 \%$, D0.1 ml $<$ V120 to the urethra, and rectum and bladder $\mathrm{V} 75 \%<1 \mathrm{~mL}$. In cases were rectum and bladder doses were not achievable, based on the prostatic interface, doses to rectum and bladder were allowed up to $\mathrm{V} 75 \%$ of $5 \mathrm{~mL}$ [29].

\section{Follow-up}

Patients were evaluated every 3 months for 2 years, and then every 6 months up to at least 5 years, and annually thereafter with PSA and testosterone testing. PSA results 
below the detection limit of the assay were entered as the respective detection limit (for example $0.1 \mathrm{ng} / \mathrm{mL}$ for a value of $<0.1 \mathrm{ng} / \mathrm{mL}$ ) for data analysis as being the most conservative estimate. Testosterone testing was discontinued once it returned into the normal range. Toxicity was reviewed according to the CTCAE v4.0 scale.

\section{PSA kinetics: nadir, bounce and failure}

PSA nadir was determined for patients with sufficient PSA follow-up, determined by at least 2 PSA measurements after completion of HT or at least 2 PSA measurements for patients not undergoing HT. Of the 48 evaluable patients, 43 patients met these criteria: treatment with HT was unknown for 3 patients, and 2 patients only had 1 post-HT PSA measurement.

Patients were counted as biochemical failures according to the Phoenix definition [30] (PSA $>2 \mathrm{ng} / \mathrm{mL}$ above the currently observed PSA nadir). PSA bounce, a benign phenomenon frequently noted after radiotherapy, was defined as an increase in PSA above the currently observed nadir greater than $2 \mathrm{ng} / \mathrm{ml}$, with a subsequent decline in PSA without further treatment. Outcomes were also computed by counting PSA bounces as failures with the date of biochemical failure the date of the increase of at least $2 \mathrm{ng} / \mathrm{mL}$ above the PSA nadir and also repeated counting them as benign events.

\section{Statistical analysis}

A single cohort of patients was uniformly treated with CF-EBRT, SBRT and, for almost all, with HT and then followed prospectively. Descriptive statistics (e.g., means, medians, proportions) were calculated to characterize patient, disease and treatment features. The KaplanMeier method was used to estimate the probability of biochemical control and of RFS with both measured from the end of RT. Biochemical failure was defined strictly according to the Phoenix definition and repeated adjusting for a PSA bounce. RFS failure was the first event of either any disease recurrence or death. Disease recurrence is defined as biochemical (PSA) failure per the Phoenix definition.

\section{Results}

\section{Patient characteristics}

Of the 48 evaluable patients (Table 1), the median follow-up was 42.7 months (range 5.3-82.9 months). The median number of PSA measurements during follow-up was 8 (range 1-24), with a median of 7 (range 1-19) PSA measurements post-HT for those treated with any HT. The median pre-treatment PSA was $10.0 \mathrm{ng} / \mathrm{mL}$ (range $3.6-150 \mathrm{ng} / \mathrm{mL}$ ), and 8 of $48(17 \%)$ had PSA $\geq 20 \mathrm{ng} / \mathrm{mL}$. 27 patients (56 \%) were Gleason 7, with 15 patients Gleason $3+4$ and 12 patients Gleason
Table 1 Baseline patient and treatment characteristics: $(n=48)$

\begin{tabular}{|c|c|}
\hline Median Age (range) & 70 years $(47.1-85.2)$ \\
\hline Median Pre-Treatment PSA (range) & $10.0 \mathrm{ng} / \mathrm{mL}(3.6-150.0)$ \\
\hline$\geq 20 \mathrm{ng} / \mathrm{mL}$ & $8(17 \%)$ \\
\hline \multicolumn{2}{|l|}{ Gleason Score } \\
\hline 7 & $27(56 \%)$ \\
\hline $3+4$ & $15(31 \%)$ \\
\hline $4+3$ & $12(25 \%)$ \\
\hline $8-10$ & $21(44 \%)$ \\
\hline \multicolumn{2}{|l|}{ T Stage } \\
\hline T1c & $12(25 \%)$ \\
\hline T2a & $13(27 \%)$ \\
\hline $\mathrm{T} 2 \mathrm{~b}$ & $3(6 \%)$ \\
\hline $\mathrm{T} 3 \mathrm{a}, \mathrm{b}$ & $20(42 \%)$ \\
\hline \# High Risk ${ }^{a}$ & $34(71 \%)$ \\
\hline Median Duration HT (range) & 6 months $(0-28)$ \\
\hline None & $3(6 \%)$ \\
\hline 3 months & $12(25 \%)$ \\
\hline $4-6$ months & $15(31 \%)$ \\
\hline 7-12 months & $8(17 \%)$ \\
\hline 24-28 months & $7(15 \%)$ \\
\hline Unknown & $3(6 \%)$ \\
\hline \multicolumn{2}{|l|}{ CTV Dose } \\
\hline 19 Gy & $23(48 \%)$ \\
\hline $21 \mathrm{~Gy}$ & $25(52 \%)$ \\
\hline Median Follow-up (range) & 42.7 months $(5.3-82.9)$ \\
\hline \multicolumn{2}{|l|}{ \# PSA Follow-up Measurements } \\
\hline Median (range) & $8.5(1-24)$ \\
\hline Median Post HT (range) & $7(1-19)$ \\
\hline
\end{tabular}

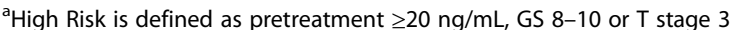

$4+3$. Twenty-one patients $(44 \%)$ had tumors that were scored as Gleason 8-10. A significant number (42\%) of patients had either extracapsular extension (T3a) or seminal vesicle invasion (T3b) on biopsy or ultrasound. The remainder of patients were T1c (25\%), T2a (27 \%), and T2b (6 \%). All patients underwent conventionally fractionated external beam radiotherapy and the majority $(88 \%)$ received hormone therapy, with $31 \%$ receiving $>6$ months of HT. $48 \%$ of patients received a boost of 9.5 Gyx2 fractions, while $52 \%$ received 10.5 Gyx2 fractions.

\section{Biochemical control}

Of the 48 evaluable patients, 6 patients had a PSA rise $\geq 2 \mathrm{ng} / \mathrm{mL}$ above the current nadir, but two of these patients subsequently had a decline in PSA and which was then determined to be a PSA bounce. Follow-up is too short to estimate overall survival with only 2 observed 
deaths as of this analysis, without either patient showing any evidence of disease.

The Kaplan-Meier estimates of biochemical no evidence of disease (bNED) with $95 \%$ confidence intervals are $95 \%(81-99 \%)$ at 3 years, $90 \%(72-97 \%)$ at 4 years, and $90 \%(72-97 \%)$ at 5 years. If PSA bounces are counted as failures, then the estimates of bNED are $93 \%(78-98 \%)$ at 3 years, $88 \%(69-96 \%)$ at 4 years, and $82 \%(61-93 \%)$ at 5 years.

\section{Recurrence free survival}

The Kaplan-Meier estimates of RFS estimates at 3, 4 and 5 years were $92 \%$ (77-97\%), $88 \%(69-95 \%)$ and $83 \%$ (62-93\%) if patients with PSA bounces are not counted as failures, and $90 \%(75-96 \%), 85 \%(67-94 \%)$ and $75 \%(53-88 \%)$ if they were.

\section{PSA nadir}

A lower PSA nadir is associated with improved clinical outcomes, and therefore we evaluated both the PSA nadir and time to nadir. For 43 patients with sufficient PSA follow-up to evaluate a PSA nadir, defined as having at least 2 PSA measurements without any HT or after completing HT, the median time to nadir was 26.2 months (range: 5.8-82.9 months), and the median PSA nadir was $0.05 \mathrm{ng} / \mathrm{mL}$ (range $<0.01-1.99 \mathrm{ng} / \mathrm{mL}$ ). The majority of these patients (72\%), had a PSA nadir $\leq 0.10 \mathrm{ng} / \mathrm{mL}$, and only 2 patients $(5 \%)$ had a PSA nadir $>1 \mathrm{ng} / \mathrm{mL}$ and both of these patients had not received any HT. These estimates of PSA nadir and time to nadir do not change if PSA bounces are not counted as failures because the values change for only 1 of the 2 patients with a PSA bounce.

The use of hormone therapy had a noticeable effect on PSA nadir: the 3 patients who did not receive any HT had the highest PSA nadir for the study cohort (0.97, 1.51 and $1.99 \mathrm{ng} / \mathrm{mL}$ ).

\section{PSA bounce}

For the 2 patients who experienced a benign PSA bounce, initial failure by the Phoenix definition occurred at 50 and 11 months, while the duration for bNED was 54 and 58, months, respectively, when considering the bounce as benign. The initial PSA nadirs for these two patients were 0.46 and 0.55 , and the maximum PSA reflecting the bounce, 4.9 , and $5.54 \mathrm{ng} / \mathrm{ml}$, respectively. These values subsequently declined to 1.3 , and $0.04 \mathrm{ng} / \mathrm{ml}$, respectively, at last follow-up.

\section{Patterns of failure}

Of the 4 patients who recurred biochemically (without PSA bounce), all recurred outside the radiation field, including 2 with peri-aortic nodal involvement, 33 and 21 months after completion of SBRT. These nodes were discovered on imaging 3 and 9 months, respectively, after biochemical failure. The third patient developed a bone metastasis at T2 79 months after radiation. A fourth patient, with T3a Gleason $4+5$ disease, developed metastatic disease to the bone discovered on PET/CT 52 months after SBRT and 4 months after biochemical failure.

\section{Toxicity}

No patient in this study had acute Grade 3 or higher genitourinary (GU) or gastrointestinal (GI) toxicity (Table 2). Twenty-three (48 \%) and $18(37 \%)$ patients had an acute grade 1 (G1) and G2 GU toxicity, while only 20 (42\%) and $5(10 \%)$ patients had an acute G1 and G2 GI toxicity, respectively. A single case of late G3 GU toxicity occurred with urinary obstruction, but resolved. 10 and 12 patients had late G1 and $2 \mathrm{GU}$ toxicity, respectively, and the majority ( $82 \%$ ) of these patients had acute G1 or 2 GU toxicity as well. Late GI toxicity was rare, with only 6 patients $(12.5 \%)$ having late grade 1 toxicity, and only 2 of these patients had acute GI toxicity. There was no G2 or higher late GI toxicity.

\section{Discussion}

The patients studied here represent an older, higher risk cohort, often typical of patients who have advanced prostate cancer and are not surgical candidates. The median age was 70 and $71 \%$ of patients were high-risk, as defined by D'Amico et al. [23]. Notably, almost half of patients $(44 \%)$ had Gleason 8 disease or higher, or

Table 2 Frequency of acute and late Genitourinary (GU) and Gastrointestinal (Gl) toxicity

\# Resolved

\begin{tabular}{|c|c|c|}
\hline \multicolumn{3}{|l|}{ Acute GU: } \\
\hline Grade 0 & 7 (15 \%) & - \\
\hline Grade 1 & $23(48 \%)$ & 16 \\
\hline Grade 2 & $18(37 \%)$ & 17 (1 dose de-escalation) \\
\hline \multicolumn{3}{|l|}{ Acute Gl: } \\
\hline Grade 0 & $23(48 \%)$ & \\
\hline Grade 1 & $20(42 \%)$ & 10 \\
\hline Grade 2 & $5(10 \%)$ & 1 \\
\hline \multicolumn{3}{|l|}{ Late GU: } \\
\hline Grade 0 & $25(52 \%)$ & - \\
\hline Grade 1 & $10(21 \%)$ & 3 \\
\hline Grade 2 & $12(25 \%)$ & 9 \\
\hline Grade 3 & $1(2 \%)$ & 1 (Obstruction) \\
\hline \multicolumn{3}{|l|}{ Late Gl: } \\
\hline Grade 0 & $42(87.5 \%)$ & - \\
\hline Grade 1 & $6(12.5 \%)$ & 1 \\
\hline
\end{tabular}

Acute Toxicity: Maximum grade observed during the first 6 months from start of protocol therapy 
extension outside of the prostate $(42 \% \mathrm{~T} 3 \mathrm{a} / \mathrm{b})$, with $67 \%$ of patients having one or both features. Consistent with the proven role of hormone therapy in increasing overall survival in high-risk patients, $88 \%$ received hormone therapy.

The results presented here compare favorably with historical series studying intermediate and high-risk patients using CF-EBRT. In RTOG 8610 [31] only $40 \%$ of patients were bNED at 5 years, while RTOG 9202 [32] and EORTC 22863 [33] found a 5 year disease free survival rate of 46.4 and $76 \%$, respectively. With the caveat that these studies contained a different patient population, occurred pre-dose escalation, and defined biochemical failure in different ways, our 5 year estimates of bNED of $90 \%$ and RFS of $83 \%$, compare favorably to the these trials.

The high rate of biochemical control for this relatively high-risk cohort may also be due to the incorporation of a hypofractionated boost, leveraging the low $\alpha / \beta$ ratio of prostate cancer. The possibility of a low $\alpha / \beta$ ratio in prostate cancer has prompted clinical investigations utilizing a hypofractionated boost delivered with HDR, providing a more appropriate comparison for the results presented here. The Seattle Prostate Institute reported a 15 year biochemical control rate of 80 and $68 \%$ for intermediate and high-risk groups, respectively [34], treated with a permanent seed implant after pelvic radiotherapy. Another randomized study comparing HDR boost of 8 Gyx2 fractions versus CF-EBRT showed PSA relapse-free survival of 97 and $96 \%$ for intermediate and high-risk patients, respectively [35]. At UCSF, 165 patients treated with a HDR boost (9.5 Gyx2 fractions or 6 Gyx3 fractions) [36] showed PSA control rates of 87 and $93 \%$ for the two dose subsets, respectively, at 5 years. A dose escalation study [37] showed BED $>268$ Gy $(\alpha / \beta=$ 1.2) delivered with HDR yielded a 10 year biochemical control rate of $81 \%$. A combined analysis of HDR boost patients [38] showed that biochemical control at 5 years was 88 and $69 \%$ for patients with one and two risk factors (stage $\geq \mathrm{T} 2 \mathrm{~b}, \mathrm{GS} \geq 7$, and PSA $\geq 10 \mathrm{ng} / \mathrm{mL}$ ), respectively. Therefore, the results presented here indicate comparable biochemical outcomes to recent HDR-boost series that employed a similar dose and fractionation.

The results presented here also compare favorably with recent SBRT series in prostate cancer, with regards to both biochemical control and toxicity (Table 3). A multi-institutional analysis [19] of localized prostate cancer treated with SBRT, with a median follow-up of 36 months, found the 5-year biochemical relapse free survival rate was 84 and $81 \%$ for intermediate and highrisk prostate cancer patients, respectively. Similar to the patients studied here, Katz [39] reported outcomes using SBRT as a boost for intermediate and high-risk patients, finding 3-year biochemical control rates of 89.5 and $77.7 \%$, respectively. Treatment was well tolerated, with only $6.8 \%$ acute G2 GU toxicity and $6.7 \%$ G2 rectal toxicity. Albeit with a follow-up of only 33 months, the long-term toxicity results are encouraging, with a rate of

Table 3 Comparison of outcomes of contemporary SBRT

\begin{tabular}{|c|c|c|c|c|c|c|c|}
\hline Author (Year) & $\mathrm{N}$ & Pt type & Dose & FU (yr) & Toxicity & Outcome & Ref \\
\hline King (2009) & 67 & $\begin{array}{l}\text { Low-risk; PSA }<10 \\
G<=3+4 ;<=T 2 \mathrm{a} / \mathrm{b}\end{array}$ & $7.25 \times 5$ & 2.7 & $\begin{array}{l}\text { GU: Grade } 4 \text { (0 \%) } 3 \text { (3 \%), } 2 \text { (5 \%), } \\
\text { and } 1 \text { ( } 23 \%) \text { respectively. } \\
\text { Rectal Grade } 3(0 \%), 2 \text { (2 \%), } \\
\text { and } 1 \text { (12.5\%). }\end{array}$ & $\begin{array}{l}(5 \text { years) } 94 \% \text { relapse } \\
\text { free survival }\end{array}$ & {$[24]$} \\
\hline Boike (2011) & 45 & $P S A \leq 20, G \leq 7, \leq T 2 b$ & $9-10 \times 5$ & 2.5 & $\begin{array}{l}\text { Gl: } 3 \text { (2\%), } 2(16 \%) ; \\
\text { GU: } 3(4 \%) ; 2(27 \%)\end{array}$ & & {$[48]$} \\
\hline Chen (2013) & 100 & $\begin{array}{l}\text { Low/intermediate } \\
\text { risk (8 high) }\end{array}$ & $7-7.25 \times 5$ & 2.3 & $\mathrm{GU} \geq 2(31 \%) ; \mathrm{Gl} \geq 2(1 \%)$ & $\begin{array}{l}\text { (2 years) } 99 \% \text { (31\% bounce, } \\
21 \% \text { late transient urinary } \\
\text { symptom flare) }\end{array}$ & {$[21]$} \\
\hline Katz (2010) & 73 & Intermediate/High Risk & $6-7 \times 3$ (Boost) & 2.75 & $2(7 \%)$ & $\begin{array}{l}\text { (3 years) } 89.5 \% \\
\text { (Intermediate); } 77.7 \% \text { (high) }\end{array}$ & [39] \\
\hline Suy (2010) & 24 & & $6.5 \times 3$ (Boost) & 0.8 & GU 2 (13\%); Gl 2 (4 \%) & & [49] \\
\hline Katz (2010) & 304 & Low/intermediate/high & $7-7.25 \times 5$ & 2.5 & $\begin{array}{l}\text { AcuteGU } 2 \text { (4.7\%); } \\
\text { Gl } 2 \text { (4\%); } \\
\text { Late } \\
\text { GU } 3(0.5 \%) ; 2(6 \%) \\
\text { GI } 2 \text { (3\%) }\end{array}$ & 4 failures (16 \% bounce) & {$[50]$} \\
\hline Jabarri (2012) & 38 & Low/intermediate/high & $\begin{array}{l}9.5 \times 4 \text { (mono) } \\
9.5 \times 2 \text { (boost) }\end{array}$ & 1 & $\begin{array}{l}\text { Acute } \\
\text { GU } 2 \text { (42\%); Gl } 2 \text { (11\%) } \\
\text { Late } \\
\text { G3 } 3 \text { (5 \%) }\end{array}$ & No failures & [25] \\
\hline King (2013) & $\begin{array}{l}1100 \\
\text { (pooled) }\end{array}$ & $\begin{array}{l}\text { Low }(58 \%) \text {, } \\
\text { intermediate (30 \%) } \\
\text { and high-risk (11\%). }\end{array}$ & $\begin{array}{l}36.25 \text { Gy in } \\
4-5 \mathrm{fx}\end{array}$ & 3 & & $\begin{array}{l}\text { (5 years) } 93 \% \\
\text { (16\% bounce) }\end{array}$ & {$[19]$} \\
\hline
\end{tabular}


91.8 \% for G2 or higher rectal toxicity-free survival. Future efforts at assessing toxicity should include patient reported outcomes.

Although long-term results are needed to definitively establish the efficacy of SBRT as a boost modality in these patients, the recent introduction of SBRT into the clinic limits the available follow-up. However, the PSA nadir provides insight into the long-term biochemical control rate [40], with lower PSA nadir associated with increased freedom from biochemical failure [15-18]. In a matched-pair analysis [41], the PSA nadir from EBRT + HDR was $0.4 \mathrm{ng} / \mathrm{ml}$, significantly lower than the $1.1 \mathrm{ng} / \mathrm{ml}$ with EBRT alone. Similarly, the University of Berlin [42] showed that $53 \%$ of patients treated with HDR boost reached a PSA nadir of $\leq 0.5 \mathrm{ng} / \mathrm{ml}$ and the William Beaumont Hospital [43] reported that $70 \%$ of patients had a PSA nadir of $<0.5 \mathrm{ng} / \mathrm{mL}$. Our results using SBRT compare favorably with these, with a PSA nadir of $0.05 \mathrm{ng} / \mathrm{mL}$ and a median time to nadir of 26 months. Of note, the PSA nadir continues to decline with longer follow-up. In a subset of these patients, we previously reported a median PSA nadir of $0.1 \mathrm{ng} / \mathrm{mL}$ at a median follow-up of 33.4 months [44]. When analyzing the PSA kinetics of SBRT monotherapy, PSA nadir also declines with longer follow-up [45]. Additional follow-up may yield an even lower median PSA nadir for this study cohort.

The toxicity reported here is similar to other series using EBRT with HDR and SBRT. RTOG 0321 used an HDR boost of 9.5 Gyx2 and noted $2.5 \%$ late G3 and greater GU and GI toxicities. An updated analysis showed that 28 of 121 evaluable cases have grade $2+\mathrm{GU}$ toxicity [46], with V120 and greater associated with increased urethral toxicity. To mitigate this, the urethra is contoured on the co-registered MRI to implement urethral sparing. Using HDR accepted dose tolerances, only a single G3 urinary toxicity was observed. A recent summary of over 1000 patients undergoing SBRT monotherapy reported only minimal decline in quality of life measures after treatment, with reported grade 3 toxicity ranging between 1 and $3 \%$ [47].

There are several limitations to this study. Although this is a relatively high-risk, older group of patients, it includes both intermediate and high-risk patients. Although testosterone was measured until it returned to the normal range, the use of HT and the slow recovery of testosterone may reduce the PSA value. Furthermore, no regular imaging of the prostate or re-biopsy was done, and therefore local control rates are only based on lack of PSA failure, and local recurrences cannot be categorically excluded. As with all non-randomized studies, patient selection can introduce bias, but this often results in patients with more adverse features being included in the study population due to the inclusion of older, nonoperable candidates. Although the median follow-up is about 4 years, longer follow-up is needed to definitively assess the efficacy of SBRT in the boost setting.

\section{Conclusion}

Hypofractionated SBRT is a feasible method to deliver the boost dose in an older, high-risk cohort, as demonstrated here. Although longer follow-up is needed, the preliminary biochemical control is similar to treatment with an HDR boost and to date, in patients with biochemical failure, there are no radiographically documented local failures. The low median PSA nadir of $0.05 \mathrm{ng} / \mathrm{mL}$ following SBRT is an improvement over standard EBRT and comparable to brachytherapy, adding to the evidence that prostate cancer has a low $\alpha / \beta$ and benefits from hypofractionated treatment. SBRT is a viable option to deliver the boost dose, achieving promising biochemical control and reduced PSA nadir with minimal toxicity without a surgical procedure.

\section{Ethics approval and consent to participate}

This study was done in accordance with the Declaration of Helsinki, and approved by the University of California Committee on Human Research, \#10-03010.

\section{Consent for publication \\ Not applicable.}

\section{Abbreviations}

CF-EBRT: Conventionally fractionated external beam radiotherapy; DFS: Disease-free survival; EBRT: External beam radiotherapy; HDR: High dose rate brachytherapy; SBRT: Stereotactic body radiotherapy; WPRT: Whole pelvic radiotherapy.

\section{Competing interests}

All authors declare no conflicts of interest.

\section{Authors' contributions}

$M A, W W, Z S, I J H, M R$, AG contributed to the design of the study. MA, WW, AG, ZS contributed to data analysis. MA, WW, ZS, IJH, MR, AG contributed to treatment design, acquisition of data, and manuscript drafting and editing. MA, WW, ZS, IJH, MR, AG have been involved in drafting the manuscript or revising it critically for important intellectual content. MA, WW, ZS, IJH, MR, AG have given final approval of the version to be published. MA, WW, ZS, IJH, $M R, A G$ agree to be accountable for all aspects of the work in ensuring that questions related to the accuracy or integrity of any part of the work are appropriately investigated and resolved.

\section{Authors' information}

MA, IJH, MR, AG all treat prostate cancer at a tertiary academic center using multiple treatment modalities, including SBRT, EBRT, and brachytherapy.

WW has a long career in biostatistics, specifically with a focus in prostate cancer.

\section{Acknowledgements}

None.

\section{Author details}

'Department of Radiation Oncology, University of California San Francisco, 1825 4th Street, San Francisco, CA 94158, USA. ²Department of Radiation Oncology, University of California San Francisco, 1600 Divisadero St. Suite H1031, San Francisco, CA 94143-1708, USA. ${ }^{3}$ Department of Radiation Oncology, Beaumont Health, 44201 Dequindre Rd, Troy, MI 48085, USA. ${ }^{4}$ Department of Radiation Oncology and Urology, University of California San Francisco, 1600 Divisadero St. Suite H1031, San Francisco, CA 94143-1708, USA. 
Received: 12 October 2015 Accepted: 7 January 2016 B.

\section{References}

1. Roach III M, Lu J, Pilepich MV, Asbell SO, Mohuidden M, Terry R, et al. Predicting long-term survival, and the need for hormonal therapy: a metaanalysis of RTOG prostate cancer trials. International Journal of Radiation Oncology. Biol Physics. 2000;47(3):617-27.

2. Kuban DA, Tucker SL, Dong L, Starkschall G, Huang EH, Cheung MR, et al. Long-term results of the MD Anderson randomized dose-escalation trial for prostate cancer. Int J Radiat Oncol Biol Phys. 2008;70(1):67-74.

3. Beckendorf V, Guerif S, Le Prisé E, Cosset J-M, Bougnoux A, Chauvet B, et al. 70 Gy versus 80 Gy in localized prostate cancer: 5-year results of GETUG 06 randomized trial. Int J Radiat Oncol Biol Phys. 2011;80(4):1056-63.

4. Dearnaley DP, Sydes MR, Graham JD, Aird EG, Bottomley D, Cowan RA, et al. Escalated-dose versus standard-dose conformal radiotherapy in prostate cancer: first results from the MRC RT01 randomised controlled trial. Lancet Oncol. 2007:8(6):475-87.

5. Brenner DJ, Hall EJ. Fractionation and protraction for radiotherapy of prostate carcinoma. Int J Radiat Oncol Biol Phys. 1999;43(5):1095-101. doi:10.1016/s0360-3016(98)00438-6.

6. Ritter M, Forman J, Kupelian P, Lawton C, Petereit D. Hypofractionation for prostate cancer. Cancer J (Sudbury, Mass). 2009;15(1):1.

7. Hodges JC, Lotan Y, Boike TP, Benton R, Barrier A, Timmerman RD. Costeffectiveness analysis of stereotactic body radiation therapy versus intensitymodulated radiation therapy: an emerging initial radiation treatment option for organ-confined prostate cancer. J Oncol Prac. 2012;8(35):e31s-e7s.

8. Hsu I, Bae K, Shinohara K, Pouliot J, Purdy J, Ibbott G, et al. Phase II trial of combined high-dose-rate brachytherapy and external beam radiotherapy for adenocarcinoma of the prostate: preliminary results of RTOG 0321. Int J Radiat Oncol Biol Phys. 2010;78(3):751-8.

9. Demanes DJ, Rodriguez RR, Schour L, Brandt D, Altieri G. High-dose-rate intensity-modulated brachytherapy with external beam radiotherapy for prostate cancer: California endocurietherapy's 10-year results. Int J Radiat Oncol Biol Phys. 2005;61(5):1306-16.

10. Astrom L, Pedersen D, Mercke C, Holmäng S, Johansson KA. Long-term outcome of high dose rate brachytherapy in radiotherapy of localised prostate cancer. Radiother Oncol. 2005;74(2):157-61.

11. Martinez AA, Pataki I, Edmundson G, Sebastian E, Brabbins D, Gustafson G. Phase II prospective study of the use of conformal high-dose-rate brachytherapy as monotherapy for the treatment of favorable stage prostate cancer: A feasibility report. Int J Radiat Oncol Biol Phys. 2001;49(1): 61-9.

12. Yoshioka Y, Nose T, Yoshida K, Inoue T, Yamazaki H, Tanaka E, et al. Highdose-rate interstitial brachytherapy as a monotherapy for localized prostate cancer: Treatment description and preliminary results of a phase I//I clinical trial. Int J Radiat Oncol Biol Phys. 2000;48(3):675-81.

13. Martinez AA, Demanes J, Vargas C, Schour L, Ghilezan M, Gustafson GS. High-Dose-Rate Prostate Brachytherapy: An Excellent AcceleratedHypofractionated Treatment for Favorable Prostate Cancer. Am J Clin Oncol. 2010;33(5):481-8. doi:10.1097/COC.0b013e3181b9cd2f.

14. Martin T, Baltas D, Kurek R, Röddiger S, Kontova M, Anagnostopoulos G, et al. 3-D Conformal HDR Brachytherapy as Monotherapy for Localized Prostate Cancer. Strahlenther Onkol. 2004;180(4):225-32. doi:10.1007/s00066004-1215-4.

15. Zietman AL, Tibbs MK, Dallow KC, Smith CT, Althausen AF, Zlotecki RA, et al. Use of PSA nadir to predict subsequent biochemical outcome following external beam radiation therapy for T1-2 adenocarcinoma of the prostate. Radiother Oncol. 1996;40(2):159-62.

16. Pollack A, Zagars GK, Antolak JA, Kuban DA, Rosen II. Prostate biopsy status and PSA nadir level as early surrogates for treatment failure: analysis of a prostate cancer randomized radiation dose escalation trial. Int J Radiat Oncol Biol Phys. 2002;54(3):677-85.

17. Lee WR, Hanlon AL, Hanks GE, Zietman AL, Perez CA. Prostate specific antigen nadir following external beam radiation therapy for clinically localized prostate Cancer: The relationship between nadir level and diseasefree survival. J Urol. 1996:156(2):450-3.

18. Shipley WU, Thames HD, Sandler HM, Hanks GE, Zietman AL, Perez CA, et al. Radiation therapy for clinically localized prostate cancer: A multi-institutional pooled analysis. JAMA. 1999;281(17):1598-604. doi:10.1001/jama.281.17.1598.
19. King CR, Freeman D, Kaplan I, Fuller D, Bolzicco G, Collins S, et al. Stereotactic body radiotherapy for localized prostate cancer: pooled analysis from a multi-institutional consortium of prospective phase II trials. Radiother Oncol. 2013;109(2):217-21.

20. Katz AJ, Santoro M, Diblasio F, Ashley R. Stereotactic body radiotherapy for localized prostate cancer: disease control and quality of life at 6 years. Radiat Oncol. 2013;8(1):118.

21. Chen LN, Suy S, Uhm S, Oermann EK, Ju AW, Chen V, et al. Stereotactic body radiation therapy (SBRT) for clinically localized prostate cancer: the Georgetown University experience. Radiat Oncol. 2013;8(1):58.

22. Freeman $D E$, King $C R$. Stereotactic body radiotherapy for low-risk prostate cancer: five-year outcomes. Radiat Oncol. 2011;6(1):1-5.

23. D'Amico AV, Whittington R, Malkowicz SB, Schultz D, Blank K, Broderick GA, et al. Biochemical outcome after radical prostatectomy, external beam radiation therapy, or interstitial radiation therapy for clinically localized prostate cancer. JAMA. 1998;280(11):969-74.

24. King CR, Brooks JD, Gill H, Presti Jr JC. Long-term outcomes from a prospective trial of stereotactic body radiotherapy for low-risk prostate cancer. Int J Radiat Oncol Biol Phys. 2012;82(2):877-82.

25. Jabbari S, Weinberg VK, Kaprealian T, Hsu IC, Ma L, Chuang C, et al. Stereotactic Body Radiotherapy as Monotherapy or Post-External Beam Radiotherapy Boost for Prostate Cancer: Technique, Early Toxicity, and PSA Response. Int J Radiat Oncol Biol Phys. 2012;82(1):228-34. doi:10.1016/j.jirobp.2010.10.026.

26. Hsu I, Chow J, Cabrera AR, Weinberg V, Speight J, Gottschalk AR, et al. Combined modality treatment with high-dose-rate brachytherapy boost for locally advanced prostate cancer. Brachytherapy. 2005;4(3):202-6.

27. Roach M, Marquez C, Yuo H-S, Narayan P, Coleman L, Nseyo UO, et al. Predicting the risk of lymph node involvement using the pre-treatment prostate specific antigen and Gleason score in men with clinically localized prostate cancer. Int J Radiat Oncol Biol Phys. 1994;28(1):33-7.

28. Fuller DB, Naitoh J, Lee C, Hardy S, Jin H. Virtual HDR CyberKnife Treatment for Localized Prostatic Carcinoma: Dosimetry Comparison With HDR Brachytherapy and Preliminary Clinical Observations. Int J Radiat Oncol Biol Phys. 2008;70(5):1588-97.

29. Descovich M, Carrara M, Morlino S, Pinnaduwage DS, Saltiel D, Pouliot J et al. Improving plan quality and consistency by standardization of dose constraints in prostate cancer patients treated with CyberKnife. J Appl Clin Med Phys. 2013;14(5):ISSN 15269914. Available at: http://www.jacmp.org/ index.php/jacmp/article/view/4333. Accessed date: 19 Jan 2016.

30. Roach lii M, Hanks G, Thames Jr H, Schellhammer P, Shipley WU, Sokol GH, et al. Defining biochemical failure following radiotherapy with or without hormonal therapy in men with clinically localized prostate cancer: recommendations of the RTOG-ASTRO Phoenix Consensus Conference. Int J Radiat Oncol Biol Phys. 2006;65(4):965-74.

31. Pilepich MV, Winter K, Lawton CA, Krisch RE, Wolkov HB, Movsas B, et al. Androgen suppression adjuvant to definitive radiotherapy in prostate carcinoma-long-term results of phase III RTOG 85-31. Int J Radiat Oncol Biol Phys. 2005;61 (5):1285-90.

32. Hanks GE, Pajak TF, Porter A, Grignon D, Brereton H, Venkatesan V, et al. Phase III trial of long-term adjuvant androgen deprivation after neoadjuvant hormonal cytoreduction and radiotherapy in locally advanced carcinoma of the prostate: the Radiation Therapy Oncology Group Protocol 92-02. J Clin Oncol. 2003;21(21):3972-8.

33. Bolla M, Collette L, Blank L, Warde P, Dubois JB, Mirimanoff R-O, et al. Longterm results with immediate androgen suppression and external irradiation in patients with locally advanced prostate cancer (an EORTC study): a phase III randomised trial. Lancet. 2002;360(9327):103-8.

34. Sylvester JE, Grimm PD, Blasko JC, Millar J, Orio III PF, Skoglund S, et al. 15Year biochemical relapse free survival in clinical Stage T1-T3 prostate cancer following combined external beam radiotherapy and brachytherapy; Seattle experience. Int J Radiat Oncol Biol Phys. 2007;67(1):57-64.

35. Guix B, Bartrina J, Tello J, Solé J, Quinzaños L, Lacorte T, et al. Treatment of intermediate-or high-risk prostate cancer by dose escalation with high-dose 3D-conformal radiotherapy (HD-3D-CRT) or low-dose 3Dconformal radiotherapy plus HDR brachytherapy (LD-3D-CRT+ HDR-B): Early results of a prospective comparative trial. Int J Radiat Oncol Biol Phys. 2010;78(3):S78.

36. Kaprealian T, Weinberg V, Speight UL, Gottschalk AR, Roach lii M, Shinohara $\mathrm{K}$, et al. High-dose-rate brachytherapy boost for prostate cancer: comparison of two different fractionation schemes. Int J Radiat Oncol Biol Phys. 2012;82(1):222-7. 
37. Martinez AA, Gonzalez J, Ye H, Ghilezan M, Shetty S, Kernen K, et al. Dose escalation improves cancer-related events at 10 years for intermediate-and high-risk prostate cancer patients treated with hypofractionated high-doserate boost and external beam radiotherapy. Int J Radiat Oncol Biol Phys. 2011;79(2):363-70.

38. Galalae RM, Martinez A, Mate T, Mitchell C, Edmundson G, Nuernberg N, et al. Long-term outcome by risk factors using conformal high-dose-rate brachytherapy (HDR-BT) boost with or without neoadjuvant androgen suppression for localized prostate cancer. Int J Radiat Oncol Biol Phys. 2004;58(4):1048-55.

39. Katz AJ, Santoro M, Ashley R, Diblasio F, Witten M. Stereotactic body radiotherapy as boost for organ-confined prostate cancer. Technol Cancer Res Treat. 2010;9(6):575-82

40. Ray ME, Thames HD, Levy LB, Horwitz EM, Kupelian PA, Martinez AA, et al. PSA nadir predicts biochemical and distant failures after external beam radiotherapy for prostate cancer: a multi-institutional analysis. Int J Radiat Oncol Biol Phys. 2006;64(4):1140-50.

41. Kestin LL, Martinez AA, Stromberg JS, Edmundson GK, Gustafson GS, Brabbins DS, et al. Matched-pair analysis of conformal high-dose-rate brachytherapy boost versus external-beam radiation therapy alone for locally advanced prostate cancer. J Clin Oncol. 2000;18(15):2869-80.

42. Deger S, Boehmer D, Roigas J, Schink T, Wernecke KD, Wiegel T, et al. High dose rate (HDR) brachytherapy with conformal radiation therapy for localized prostate cancer. Eur Urol. 2005;47(4):441-8.

43. Martinez A, Gonzalez J, Spencer W, Gustafson G, Kestin L, Kearney D, et al. Conformal high dose rate brachytherapy improves biochemical control and cause specific survival in patients with prostate cancer and poor prognostic factors. J Urol. 2003;169(3):974-80.

44. Anwar M, Weinberg V, Hsu I, Roach M, Gottschalk A. Outcomes of Hypofractionated SBRT Boost for Intermediate-and High-Risk Prostate Cancer: A Single Institutional Prospective Study. Int J Radiat Oncol Biol Phys. 2013;87(2):S105-6.

45. Anwar M, Weinberg V, Chang AJ, Hsu IC, Roach lii M, Gottschalk A. Hypofractionated SBRT versus conventionally fractionated EBRT for prostate cancer: comparison of PSA slope and nadir. Radiat Oncol. 2014;9(1):42.

46. Hsu I, Hunt D, Straube W, Pouliot J, Cunha A, Krishnamurthy D, et al. Dosimetric analysis of radiation therapy oncology group 0321: The importance of urethral dose. Pract Radiat Oncol. 2014;4(1):27-34.

47. King CR, Collins S, Fuller D, Wang P-C, Kupelian P, Steinberg M, et al. Healthrelated quality of life after stereotactic body radiation therapy for localized prostate cancer: results from a multi-institutional consortium of prospective trials. Int J Radiat Oncol Biol Phys. 2013;87(5):939-45.

48. Boike TP, Lotan Y, Cho LC, Brindle J, DeRose P, Xie X-J, et al. Phase I doseescalation study of stereotactic body radiation therapy for low-and intermediate-risk prostate cancer. J Clin Oncol. 2011;29(15):2020-6.

49. Suy S, Park HU, Kim JS, Sherer BA, Collins BT, Satinsky AN, et al. A pilot study of intensity modulated radiation therapy with hypofractionated stereotactic body radiation therapy (SBRT) boost in the treatment of intermediate-to high-risk prostate cancer. Technol Cancer Res Treat. 2010;9(5):453-462.

50. Katz AJ, Santoro M, Ashley R, Diblasio F, Witten M. Stereotactic body radiotherapy for organ-confined prostate cancer. BMC Urol. 2010;10(1):1.

\section{Submit your next manuscript to BioMed Central and we will help you at every step:}

- We accept pre-submission inquiries

- Our selector tool helps you to find the most relevant journal

- We provide round the clock customer support

- Convenient online submission

- Thorough peer review

- Inclusion in PubMed and all major indexing services

- Maximum visibility for your research

Submit your manuscript at www.biomedcentral.com/submit 